\title{
$\mathrm{PH} 100_{\text {debate }}$
}

a debate Repositorios y redes sociales académicas para la transferencia del conocimiento abierto

| coordina Remedios Melero Melero

\section{La consideración y utilización de las redes sociales académicas por los investigadores noveles españoles}

\author{
Blanca Rodríguez-Bravo | Dpto. Patrimonio Artístico y Documental, Universidad de León \\ URL de la contribución <www.iaph.es/revistaph/index.php/revistaph/article/view/4649>
}

En estas breves líneas me propongo presentar algunos resultados del proyecto internacional Early Career Researchers: the Harbingers of Change? ${ }^{1}$ que persigue determinar si la nueva ola de investigadores está contribuyendo a cambiar el escenario de la comunicación académica. Se parte de la premisa de que, en el caso de los investigadores más jóvenes, sus convicciones de millenials y su afición a las redes sociales puede determinar su preferencia por: utilizar nuevas vías de acceso a la información y nuevos modelos de publicación; contribuir a la transparencia; compartir información; o atender a las métricas alternativas.

A efectos de este proyecto se entiende por Early Career Researchers (ECRs) aquellos investigadores que están realizando el doctorado o bien son doctores pero que no han alcanzado una posición de estabilidad.

En una primera fase, el estudio longitudinal (2016-2018) consistió en la realización de un centenar de entrevistas que se repitieron durante tres años a ECRs donde dos terceras partes procedían de ámbitos científicos y una tercera parte de ciencias sociales. Los instrumentos de recolección, informes y publicaciones derivadas se relacionan en la página de Ciber Research Ltd.

Las entrevistas se realizaron en China, España, Francia, Malasia, Polonia, Reino Unido y USA. En España se entrevistó a 18 jóvenes investigadores de 18 instituciones diferentes.

El propósito de la segunda fase era extender el estudio a una población mayor y más diversa de Early Career Researchers (ECRs) que incluyera a los científicos de humanidades. El cuestionario -accesible entre mayo y julio de 2019- recolectó las opiniones y prácticas de
1.600 investigadores de los que un centenar fueron españoles.

En las entrevistas (RODRÍGUEZ-BRAVO; NICHOLAS, 2019), desarrolladas durante tres años consecutivos, los ECRs españoles, muy mediatizados por su necesaria búsqueda de un trabajo estable, se muestran extremadamente focalizados en la publicación en revistas bien posicionadas.

Con todo, son favorables a comunicar su investigación en las redes sociales y/o comunidades online, pero solo una vez publicada. Consideran que pueden ganar atención y visibilidad y con ellas incrementar su reputación. Si no lo hacen más es por temor a transgredir las normas de las revistas.

ResearchGate, pero también Twitter, han ido cobrado mayor relevancia durante el periodo estudiado. Gestionar

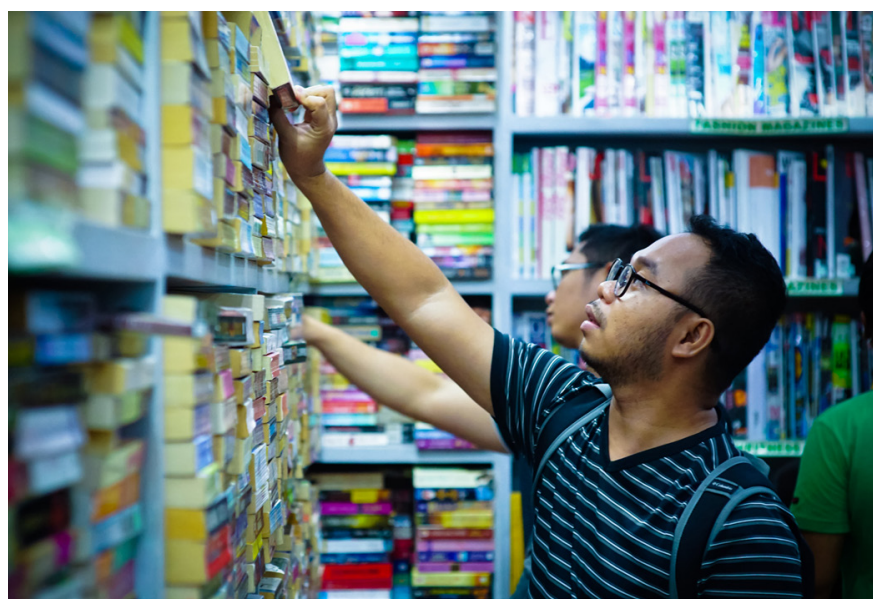

Early Career Researchers son aquellos investigadores que no han alcanzado aun una posición de estabilidad 
correctamente la imagen digital empieza a preocupar a estos investigadores que son más conscientes de las ventajas que pueden obtener si invierten más tiempo en gestionar su identidad en estas plataformas.

Un investigador apunta: "Las redes sociales dan visibilidad, pero la mayor exposición de nuestro trabajo puede incrementar la reputación porque puedes obtener citas, invitaciones, nuevos contactos, etc."

Las redes sociales académicas se utilizan también para descubrir y acceder a la investigación de los colegas, participar en discusiones, son fuente de inspiración de nuevas ideas de investigación y promueven la colaboración.

Los investigadores creen en los beneficios que les puede aportar la colaboración con otros investigadores de su área, de otras áreas y de otros países. Básicamente porque pueden aprender de otros, les permite utilizar técnicas más avanzadas, y ello redundará en mejores trabajos y en mayor impacto.

"La colaboración mejora el impacto porque permite usar mejores técnicas, aprender más y publicar mejores trabajos en mejores revistas", señala una investigadora.

Los investigadores españoles son conscientes, por tanto, de las ventajas de explotar las funcionalidades de las redes sociales pero se ven limitados por la escasez de tiempo que pueden dedicarles.

Por el contrario, respecto a los repositorios la tónica general es de desinterés. Muchos investigadores hasta desconocen su existencia, y si la conocen no ven la utilidad de invertir su tiempo en el auto-archivo. Algunos señalan que ya se ocupan de ellos los bibliotecarios.

En 2019 seguimos indagando en las actitudes y prácticas de los ECRs a través de un cuestionario (RODRÍGUEZBRAVO; NICHOLAS, 2020). La información recogida confirma esencialmente la que recabamos en las entrevistas.
Los ECRs españoles, si bien afirman hacer un esfuerzo por adoptar los principios de la ciencia abierta y por compartir la investigación, no parece que en la práctica lo lleven a efecto de manera muy decidida. Se muestran cautos a la hora de compartir resultados no publicados, se limitan a compartir en redes sociales preprints y no muestran interés por publicar en abierto utilizando los repositorios institucionales o temáticos. El informe Ithaka US confirma este desinterés en depositar los productos de la investigación en repositorios en el entorno americano (BLANKSTEIN; WOLFF-EISENBERG, 2019).

Esta situación obedece al mayor esfuerzo que requiere autoarchivar en los repositorios frente a las facilidades que ofrecen a los autores las redes académicas para incorporar sus documentos. Los ECRs persiguen resultados inmediatos con el menor esfuerzo posible y valoran los servicios que estas redes proporcionan.

Las respuestas obtenidas indican que el uso de las redes sociales se dirige principalmente a tres finalidades: mantenerse actualizados en el campo de investigación; interactuar con los colegas, que puede conducir a la colaboración en la investigación; y compartir la investigación realizada que es el medio principal para incrementar el impacto de sus trabajos.

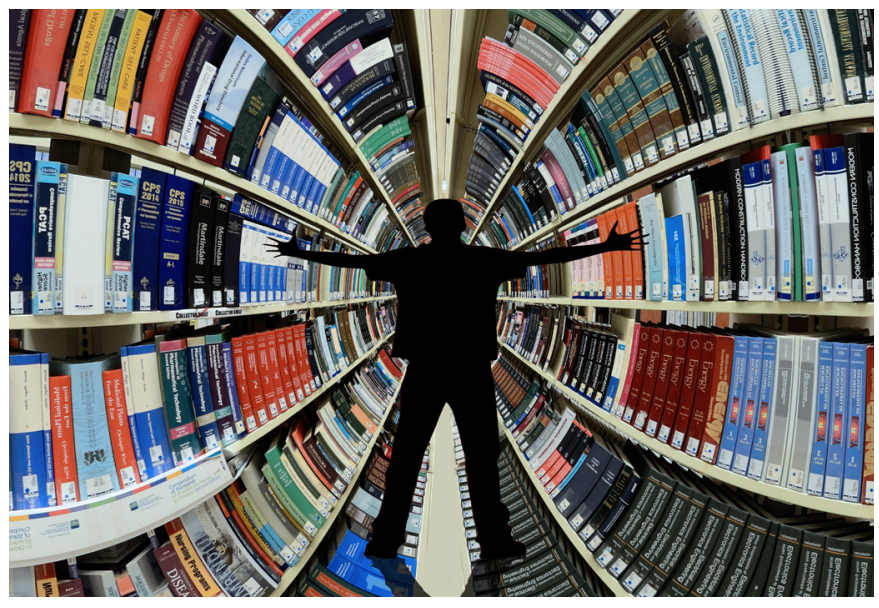

Los ECRs españoles se muestran cautos a la hora de compartir resultados no publicados 
_a debate Repositorios y redes sociales académicas para la transferencia del conocimiento abierto | coordina Remedios Melero Melero

Las redes sociales son útiles como vías de acceso a los contenidos y como medios de establecer contactos que terminen en colaboraciones.

Conseguir el impacto necesario requiere de una labor previa de difusión y los investigadores cada vez están más convencidos de la utilidad de mostrar y compartir sus publicaciones a través de las redes sociales. Los ECRs españoles consideran que estas plataformas, ya sean generalistas o académicas, les aportarán visibilidad y lecturas que podrán transformarse en reputación y en citas.

Finalmente, cuestionados acerca de qué redes o plataformas son más útiles para su investigación, ResearchGate, Twitter y Facebook son las más señaladas y en ese orden. La preferencia por redes de corte académico como ResearchGate es indicio de la búsqueda de la reputación, prioritaria en el colectivo de investigadores que analizamos que todavía tienen que consolidar su presencia en la Academia.

\section{NOTAS}

1. http://ciber-research.eu/download/20181218-Harbingers3_Final_Report-Nov2018.pdf

\section{BIBLIOGRAFÍA}

- BLANKSTEIN, M.; WOLFF-EISENBERG, C. (2019) Ithaka S+R US Faculty Survey 2018: Report [en línea], April 12, 2019. Ithaka S+R <https://sr.ithaka.org/wp-content/uploads/2019/03/ SR-Report-US-Faculty-Survey-2018-04122019.pdf> [Consulta: 27/04/2020]

- RODRÍGUEZ-BRAVO, B.; NICHOLAS, D. (2019) Reputación y comunicación científica: investigadores españoles en el inicio de su carrera. El profesional de la información, vol. 28, n. ${ }^{\circ} 2$, 2019, pp. 1-16 <https://recyt.fecyt.es/index.php/EPI/article/ view/pi.2019.mar.03> [Consulta: 27/04/2020]

- ROdRígueZ-BRAVO, B.; NICHOLAS, D. (2020) Descu brir, leer, publicar, compartir y monitorizar el progreso: comportamiento de los investigadores junior españoles. El profesional de la información, vol. 29, n. ${ }^{0} 5$ (en prensa) 